\title{
Conservation news
}

\section{Pigeon and dove specialist group launched}

Columbiformes (pigeons and doves) are currently one of the most threatened avian orders-a consequence of a range of pressures, including habitat loss and degradation, invasive alien species, hunting and climate change. The impacts of these are exacerbated by the restricted ranges of many species (Columbiformes have a propensity for endemism, particularly on islands). Of the 354 extant species, $72(20 \%)$ are currently threatened with extinction and 47 are categorized as Near Threatened. A long list of extinct species includes the passenger pigeon Ectopistes migratorius and dodo Raphus cucullatus.

Despite this, the order has not received a level of attention proportionate to the number of species that are threatened, especially considering the vital ecological roles of many Columbiformes (e.g. as seed dispersers and keystone species in tropical forests). This is evident in the paucity of information on the status of wild populations: the data used to assess population sizes for most threatened Columbiformes is ranked as 'poor' by BirdLife International.

A determination to reverse this trend was the impetus behind the inauguration in March 2021 of the IUCN Species Survival Commission (SSC) Pigeon and Dove Specialist Group, hosted by Toledo Zoo in Ohio, USA. The founding membership comprises conservation practitioners, aviculturists, academics and experts with specialist knowledge in Columbiform phylogeny, avian medicine, wildlife trade and the control of invasive mammalian predators.

Key activities of the Specialist Group will include collaborating with BirdLife International to assess and monitor the status of Columbiform species, raising the profile of threatened pigeons and doves, and convening expertise for conservation. These activities will entail facilitating communication between organizations involved in ex situ and in situ programmes and between the scientific community and the holders of traditional ecological knowledge. The group intends to partner with the SSC Conservation Planning Specialist Group to draft action plans for priority species, will seek to source the funding required for the implementation of these plans, and will prioritize monitoring and evaluation of conservation efforts.

We believe this group has the potential to become a driving force for the conservation of Columbiformes worldwide, and we are committed to developing a diverse and genderbalanced network of people who will help achieve this. Prospective members are encouraged to contact the group Co-Chairs, Joe Wood and Chuck Cerbini.

JOE WOOD (๑ orcid.org/0000-0001-8173-4249) Toledo Zoo, Toledo, Ohio, USA.E-mail joe.wood@toledozoo.org
CHUCK CERBINI (@ orcid.org/0000-0001-7198-9934) Wildlife Conservation Society, New York, USA

This is an Open Access article, distributed under the terms of the Creative Commons Attribution licence CC BY 4.0

\section{Lost and found: rediscovery of the extinct tentacled butterfly ray Gymnura tentaculata in Iranian waters}

The tentacled butterfly ray Gymnura tentaculata was described in 1841 from specimens believed to have been collected in the Red Sea. The historical range of this inshore, benthic species extended throughout the northern Indian Ocean from the Red Sea to the western Bay of Bengal. It is one of only two butterfly ray species known to occur in the north-west Indian Ocean. Despite intensive surveys throughout the region, it had not been seen in the coastal waters off India since 1973 and the last records were from Pakistan in 1986. In 2017 the species was assessed as Critically Endangered and flagged as Possibly Extinct on the IUCN Red List of Threatened Species.

However, during a monitoring programme in southern Iranian waters, the species was found to represent c. $15 \%$ of the ray bycatch in trawl fisheries. In 39 of 96 trawl hauls surveyed during October 2019-November 2020, a total of 367 individuals (disc width $14-85 \mathrm{~cm}$ ) were recorded from the Gulf of Oman and eastern Persian Gulf. Based on this discovery and the absence of recent records from elsewhere (the species has not been recorded in recent elasmobranch-specific surveys in the Red Sea or Persian Gulf, or from Indian or Pakistani waters), this region appears to be the species' last stronghold.

Fishing pressure is intense throughout the species' former and current range, where severe ongoing declines in all ray populations have been reported. Surveys in Iranian waters combined with previous data suggest the tentacled butterfly ray population has declined by c. $86 \%$ over the past 30 years. The rediscovery of this Critically Endangered ray highlights the importance of monitoring landings.

We thank the Iranian Fisheries Science Research Institute, Prince Bernhard Nature Fund, and the Marine Conservation Action Fund of New England Aquarium for supporting this project, and a Future For Nature Award to MR-A.

MoHSEN REZAIE-ATAGHOLIPOUR (○ orcid.org/0000-0003-04560411) Qeshm Environmental Conservation Institute, Qeshm Island, Hormozgan Province, Iran. E-mailmra@qeci.org

RIMA W. JABADO (○ orcid.org/0000-0001-6239-6723) Elasmo Project, Dubai, United Arab Emirates 